\title{
$(\mathrm{cc})) \mathrm{BY}-\mathrm{ND}$
}

\section{Petrarch's Early Manuscripts and Incunabula in the Oregon Petrarch Open Book}

\section{Massimo Lollini, University of Oregon}

\begin{abstract}
Working from transcriptions generated through the T-PEN program at St. Louis University, the collaborators of the project "Petrarch's Early Manuscripts and Incunabula in the Oregon Petrarch Open Book (OPOB)" are presently digitizing and encoding in TEl P5 two key interpretative copies of Petrarch's Rerum vulgarium fragmenta: the late fourteenth-century manuscript copy from the Queriniana Library in Brescia, D II 21, and the Queriniana Library's copy of the first printed edition (editio princeps) of the Rerum vulgarium fragmenta edited presumably by Cristoforo [Berardi?] and published by Vindelin de Speier (Spira) in Venice in 1470. The first part of the article traces a brief history of the Oregon Petrarch Open Book and the last section introduces a future project, "Texts, Images and Interpretation in the OPOB."
\end{abstract}

\section{The Oregon Petrarch Open Book}

The Oregon Petrarch Open Book (OPOB) is a working repository-hypertext in and around Francis Petrarch's Rerum vulgarium fragmenta, or Collection of Fragments in Vernacular (also known as the Canzoniere). The original title given by Petrarch to his collection of poems literally translates Fragments of scattered things in vernacular, it conveys the idea of an ongoing project that in taking shape and form maintains a fragmentary, uncertain, and open nature. Using open source software, we are building a flexible and comprehensive structure of digital assets that promotes innovative research, preservation, and pedagogy, based on international collaboration among scholars and institutions, and continues Petrarch's model of an open, evolving, and unfinished work.

This project started in 2003 with the goal of deepening our understanding of the future of the book in the context of digital scholarship. It was seen as a critical opportunity to integrate different technologies and resources stretching from manuscript, to book culture, up to late print culture. Since its inception, the project has been particularly interested in taking advantage of digital technology 
to create new conditions to study and teach Petrarch's Rerum vulgarium fragmenta (henceforth, Rvf) through its evolution and afterlife in translations, rewritings, and intersemiotic transpositions. The open book idea presents this central work of world literature as an ongoing project, not as a finished product. Thus, the OPOB shares the idea that digital technology favors a movement "away from the notion of a single-text 'definitive edition" (Finneran). The project aims to provide multiple versions of the $R v f$ in different formats, being aware that a special concern with versioning is a distinctive feature of contemporary editing (Bryant).

The Canzoniere is the perfect text for designing a system around the idea of the open book. Not only is it the most influential collection of poetry in the European tradition, but it is constructively and profitably read as a work-inprogress and as an unfinished text; Petrarch continued to produce different versions of his collection and shift the order of the poems until his death in 1374. Roland Greene sees in Petrarch's Canzoniere the founding moment of Western lyric sequence that influenced the lyrical discourse not only of European poets but also of North American and Latin American poets such as Walt Whitman and Pablo Neruda. It is not by chance that an important digital humanities project such as "The Whitman Archive" has encountered problems similar to those that the OPOB is facing: representing the unfinished and evolving nature of Whitman's Leaves of Grass, which like the Rvf may be read as a work-in-progress, an unfinished text that, in the context of nineteenth-century print culture, underwent continual addition, revision, and reordering throughout the poet's life.

In 2010 the OPOB received a Digital Humanities Start-up Level II fellowship. This grant triggered collaboration with Web designer Travis Shea and the University of Oregon Libraries, making available new versions of Petrarch's $R v f$ in digital format, from the diplomatic edition prepared by Ettore Modigliani in 1904 - a transcription of the manuscript Vatican Latin 3195, on which Petrarch was still working at the time of his death - to the most recent critical edition prepared by Giuseppe Savoca (2008). Other important resources have been included, such as Alessandro Vellutello's 1525 commentary of the Rvf and the complete 1555 French translation by Vasquin Philieul. Finally, the OPOB was able to develop an international collaboration, involving among others Ennio Ferraglio, director of the Queriniana Italian Library in Brescia, who gave to the project permission to use digital copies of one important early manuscript of the $R v f$ (Codex Queriniano D II 21) and the earliest incunabulum of the Rvf (Queriniano G V 15) from the library. We also worked with Peter Kuon (University of Salzburg), Paola Vecchi Galli (University of Bologna) and, for a short period, Wayne Storey (Indiana University). 
During the NEH grant period, we enhanced the functionality of the existing database software and of specific tools, such as "Compare poems and assets," by providing multiple moveable containers of selectable content, text, images, audio or video. The OPOB encourages an active and polyphonic reading; allowing different platforms of critical attention by using the link Compare poems and assets in the upper right of the screen:

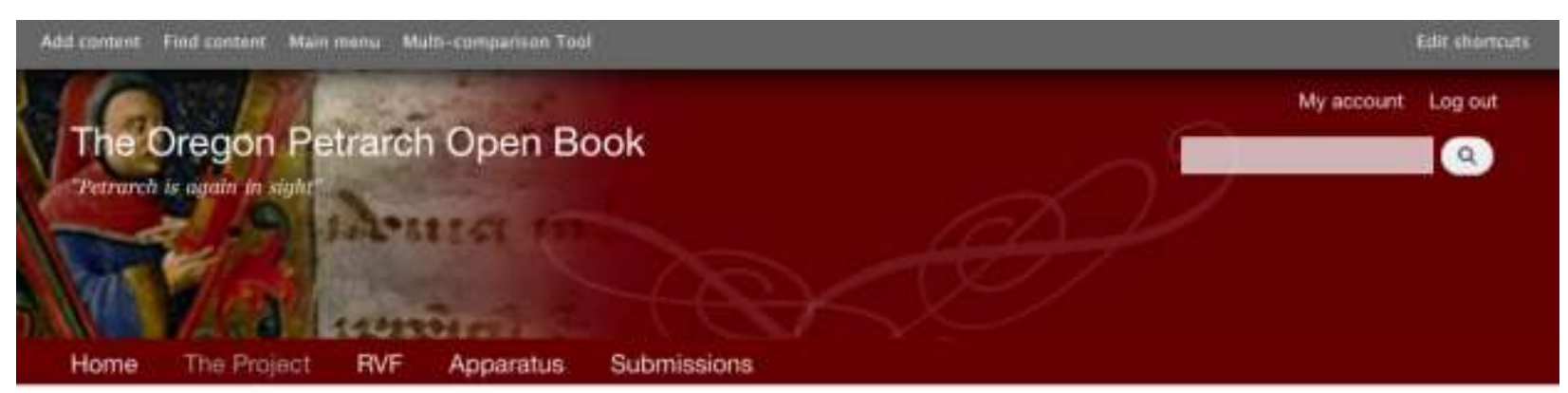

Compare poems and assets

- Advisory Board

- Credits

- Project Staff

- Help

- Video Introduction

- Contact Us
Help

View Edit Rlevisions $\log$ Dovel

The RVF menu allows user to read Petrarch's Rerum vulgarium fragmenta (Canzoniere) in different forms, media and formats by clicking on the links on the left side of the page:

The user may compare multiple versions of the original text in Italian, for example the Modigliani Diplomatic Edition and the recent critical edition prepared by Giuseppe Savoca: 


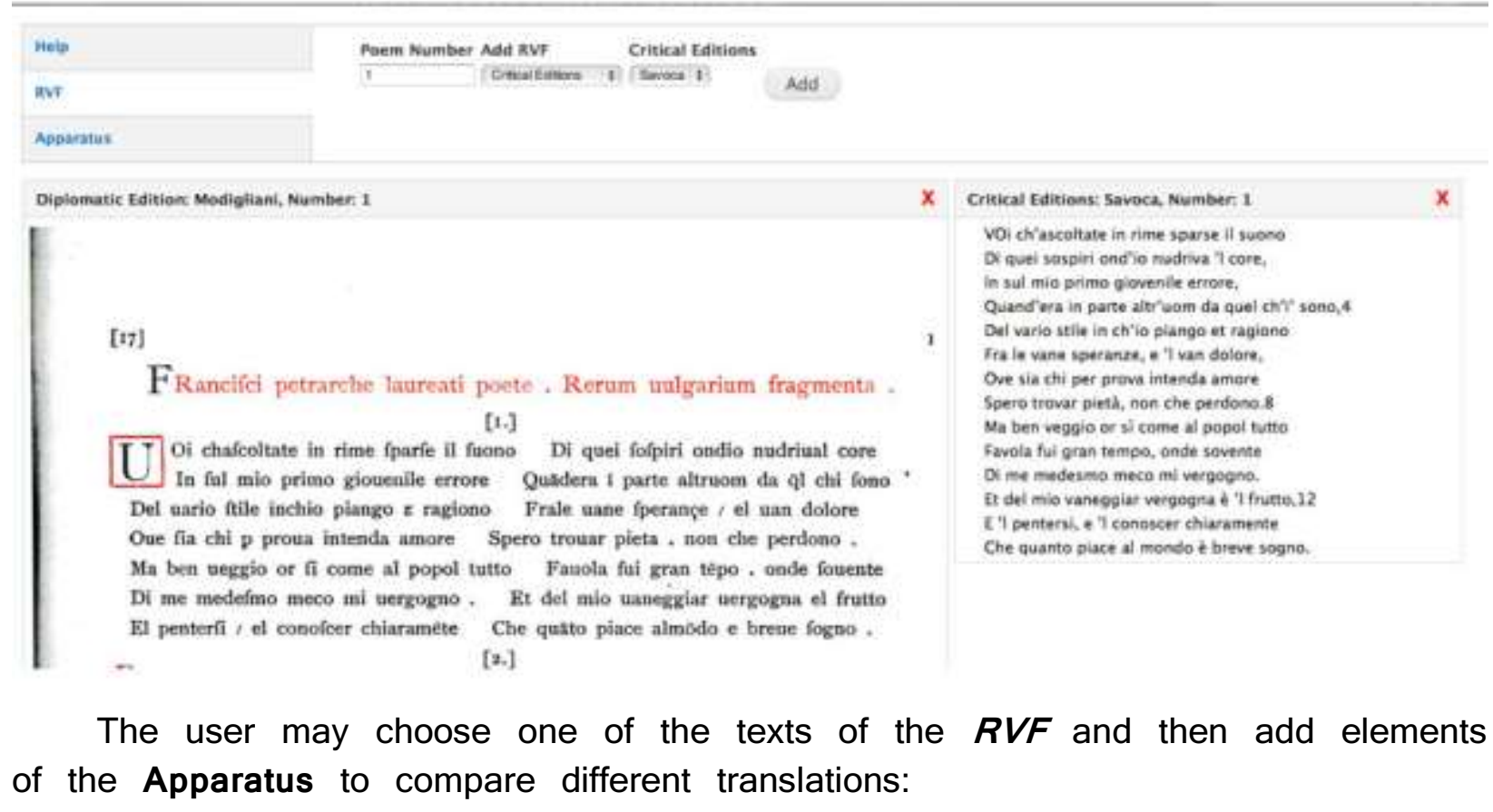

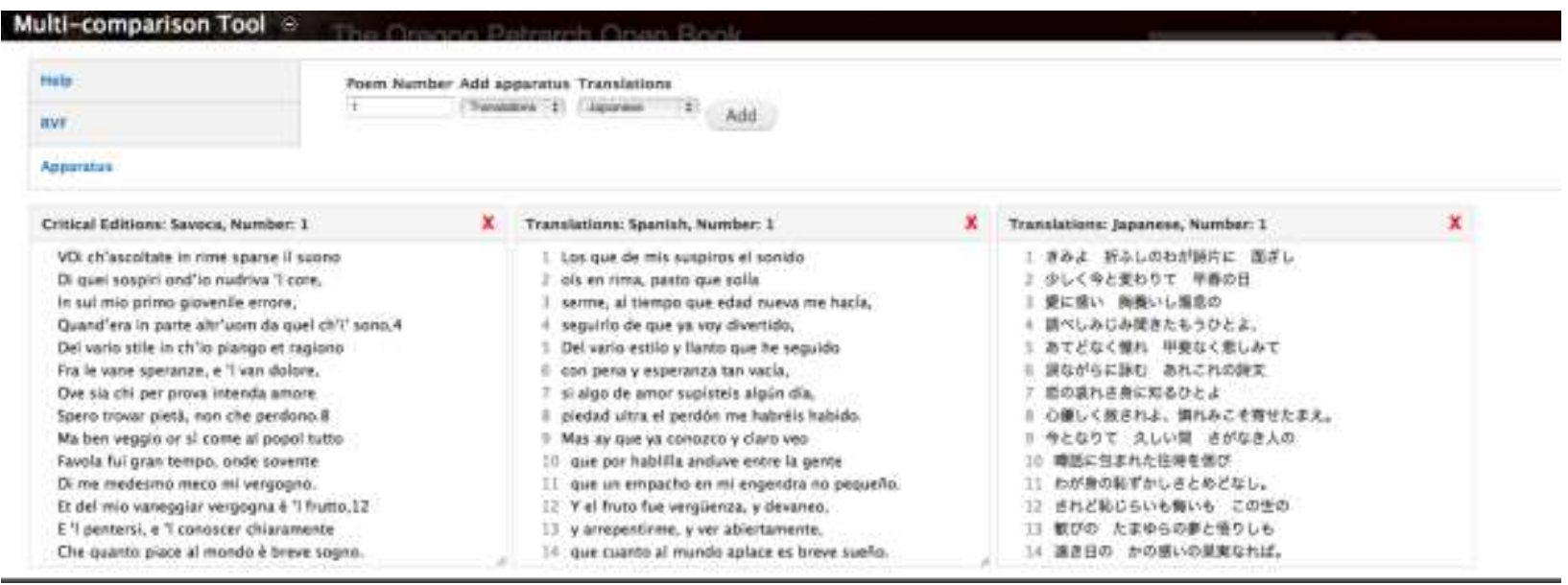

Or to consult paraphrases, summaries and tweets: 


\section{Multi-comparison Tool}

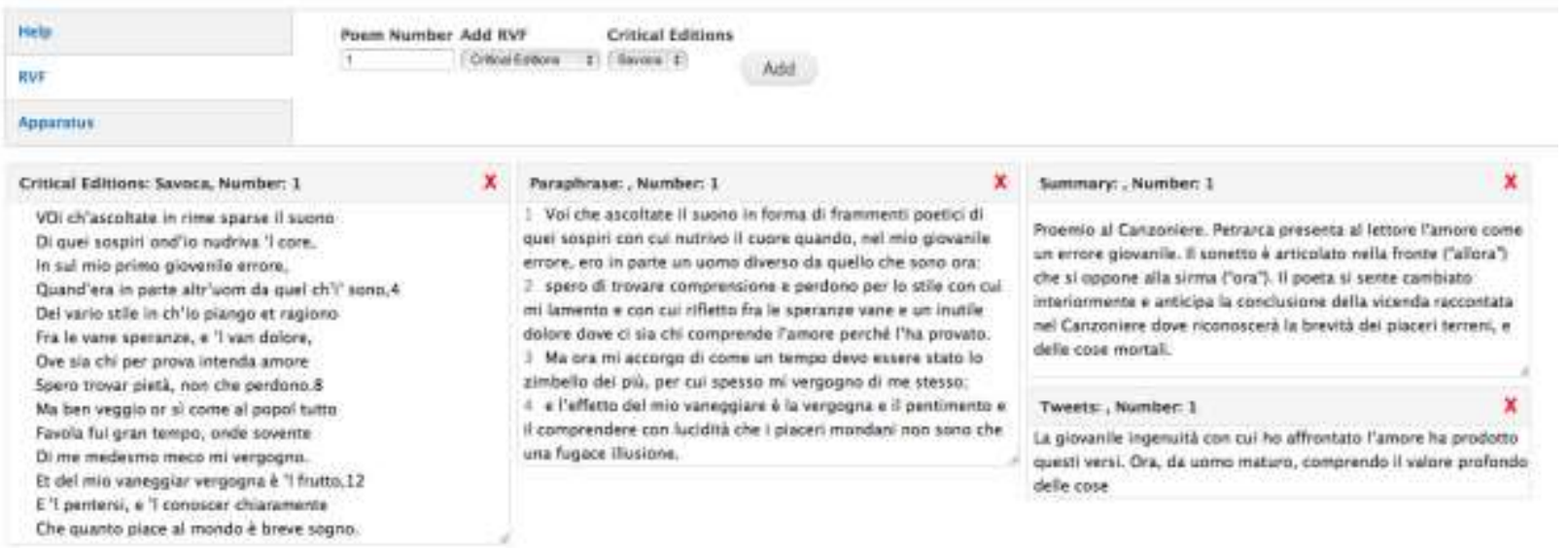

One can access an important commentary, Vellutello's Le volgari opere del Petrarcha con l'esposizione di Alessandro Vellutello (1525):

\section{Multi-comparison Tool $\odot$}

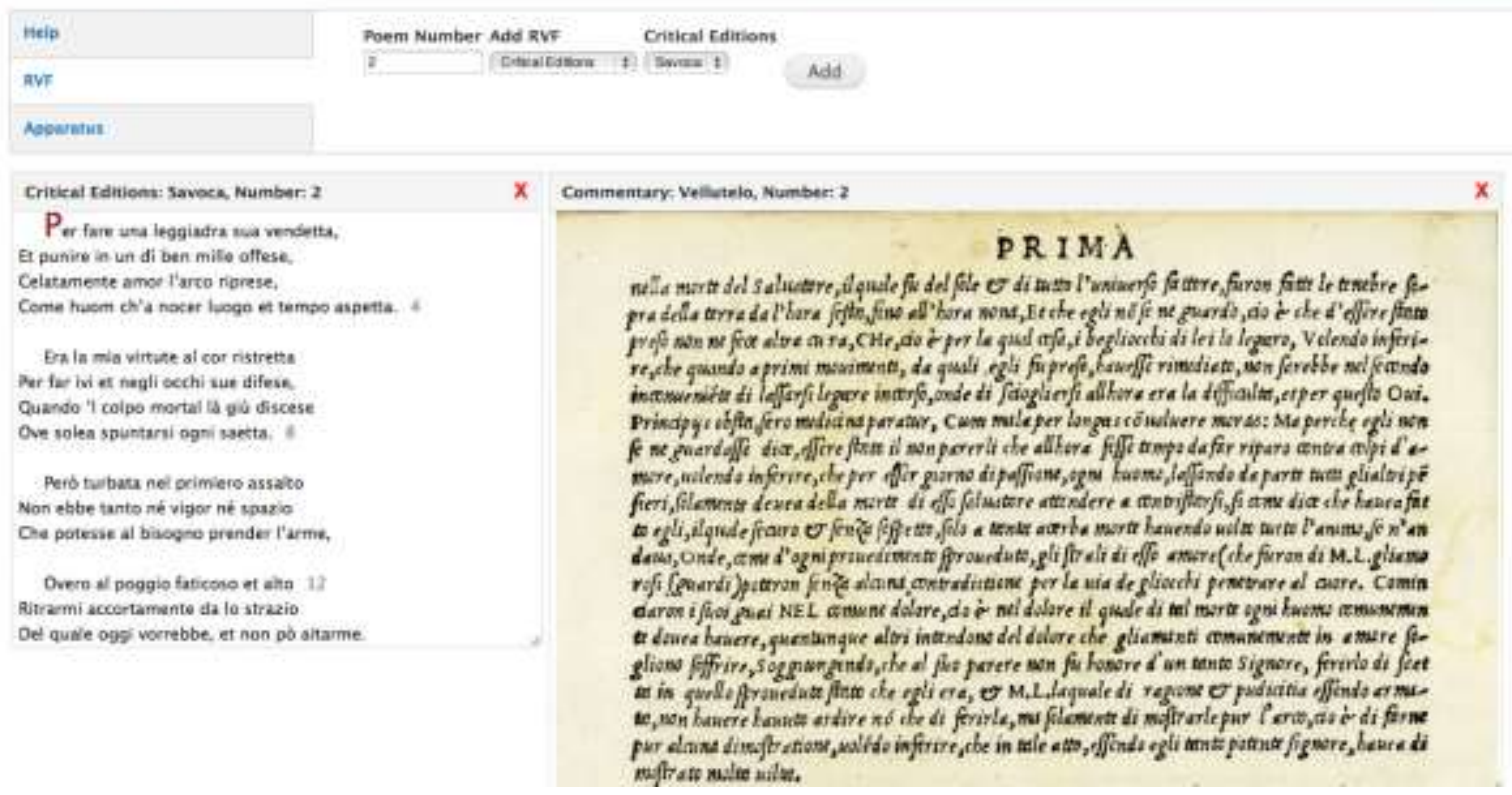

Or see archives (visual, audio, and textual) related to specific poems: 
Multi-comparison Tool

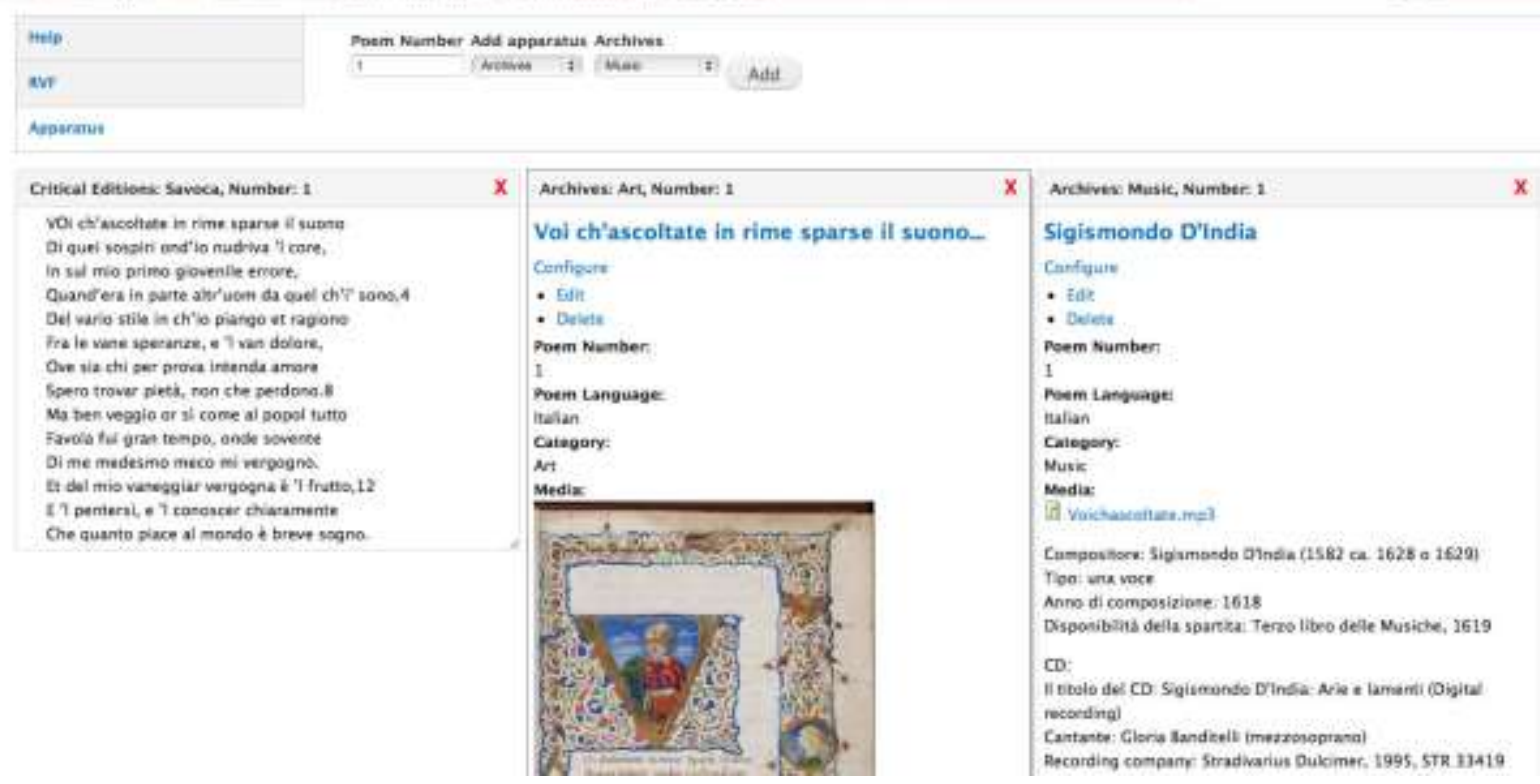

The Digital Humanities Start-up Level II grant was instrumental in supporting an upgrade to the website infrastructure using the latest version (7) of the open source Content Management System, Drupal. Thanks to the collaboration of Karen Estlund, Head of the Digital Scholarship Center at the University of Oregon, we were able to link the OPOB site to the UO Libraries' digital repository: https://oregondigital.org/cdm4/browse.php?CISOROOT=/petrarch

Tools were applied to the text images included in the repository that allow the user to zoom and pan around within a window in order to make comparisons to other content more accessible. The texts of the library repository are now linked to the $\mathrm{OPOB}$ and at the same time have been made available for anyone to access and use for research. The metadata is also available via the Open Archives Initiative Protocol for Metadata Harvesting, making the texts available to be re-used in other projects.

The new site of the OPOB was officially made available to the public at the end of October 2011. We call OPOB the open-book initiative, partly in homage to the open-source software movement whose tools we are using (Drupal, PHP, MySQL, XTF, shared-canvas), and partly in reference to the way computer-mediated communication technology and online professional networking has opened up new ways of building academic communities to learn and collaborate. But mostly we call it "open" because our approach articulates new interdisciplinary paths for reading and learning in the Romance languages and literatures, comparative literature, linguistics, and translation studies. Given the importance of Petrarch's Canzoniere in the formation of modern Western lyric discourse, only a richly annotated hypertextual approach can do justice to the 
complexity and richness of the cross-cultural and interlingual connections involved in the phenomenon of Petrarchism.

As mentioned above, the new site includes the most recent critical edition of Petrarch's Canzoniere prepared by Giuseppe Savoca. This edition is different from all previous editions and arguably the most innovative in its editorial decisions, made possible by the use of digital technology and ultraviolet analysis. Most innovations are related to punctuation. For instance, the interpretation of sonnet 179 changes in the new edition because of a virgula at the end of a verse. Preparation of the edition involved approaching the Canzoniere with a view to establishing concordances/correlations among all aspects of its "lexicon" (literally lexical, graphemic, and visual). Savoca holds that his use of computer technology, both on the lexical level and in the treatment of images, made the difference with respect to the traditional philological approach, both in analysis and in the properly editorial phase. Proceeding by concordance/correlation implies that, before making any editorial decision, one must compare all analogous elements of the work and be aware of the received philological tradition. Savoca is convinced that today only computational analysis can provide a scientific basis for our textual analyses. Digital treatment of a text, he writes, allows us to move from the syntagm to the paradigm; that is, it puts us in contact with the system specific to the text that we wish to understand and publish. Nonetheless, Savoca is aware that "the philology of a text is a continuously open technical and cognitive process" and that, as a consequence, the hermeneutic task of the interpreter is inexhaustible and should always be philologically oriented (vii).

Philology is the master key of the OPOB that takes us one step further toward the computer-assisted reconstruction of the text envisioned by Savoca. This is done through the creation of a hypertext that aims at documenting the historical evolution of the Canzoniere from manuscript culture to print and digital culture. From this perspective, all editions of the Canzoniere previous to Savoca's maintain their value and utility as a witness to the multiple lives of the text and its reception and translations. For this reason, we decided to keep in our hypertext the previous critical edition prepared by Contini. In the OPOB it is possible to switch from one edition to the other using the following, drop-down menu: 


\section{RVF \\ - Critical Editions \\ - Diplomatic Editions \\ - Manuscripts \\ - Incunabula \\ - Bibliography}

\section{Critical Editions}

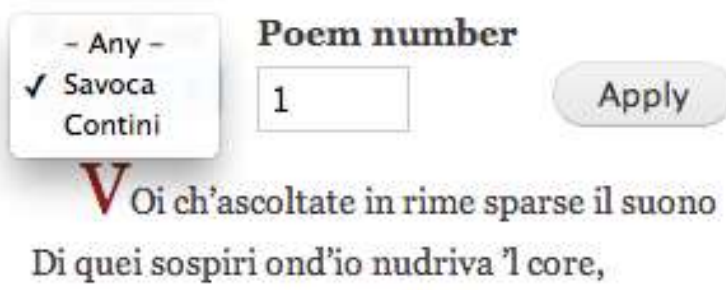

\section{Transcribing and Encoding Codex Queriniano D II 21 and Incunabulum Queriniano G V 15}

Having built a solid infrastructure and productive collaborative ties with local, national, and international colleagues, the OPOB decided to pursue further collaborative exchange and interoperability by implementing TEI (Text Encoding Initiative) encoding in key digital assets of the OPOB. In fact, the TEl has become an essential component of e-philology, not only by developing an interchange language that allows scholars to exchange information but also by developing a new data description language that improves the ability to describe textual features. In 2012 we received an American Council of Learned Societies Digital Innovation grant (ACLS) for the collaborative project "Petrarch's Early Manuscripts and Incunabula in the Oregon Petrarch Open Book." This project is an open source, open access initiative designed for students, scholars, teachers, and translators to read and investigate selected manuscripts and early printed editions of Petrarch's magnum opus that have been instrumental to its interpretation from its first release in 1362 until today. Working from transcriptions generated through the T-PEN program at St. Louis University (Transcription for Paleographical and Editorial Notation), the collaborators of the project are presently digitizing and encoding in TEI P5 two key interpretative copies of Petrarch's Rvf. the late fourteenth-century manuscript copy from the Queriniana Library in Brescia, D II 21, and the Queriniana Library's copy of the first printed edition (editio princeps) of the Rvf edited by Cristoforo [Berardi?] and published by Vindelin de Speier (Spira) in Venice in 1470.

The encoding of the transcriptions utilizes standard TEI P5 modules to produce schemas in DTD, W3C, and Relax NG formats. Additional validation will be performed by a Schematron schema. Massimo Lollini is leading the transcription, encoding, and testing processes; his team include as collaborators and consultants: 1) Karen Estlund, Head, Digital Scholarship Center, UO Libraries; 
2) John Russell, Scholarly Communications Librarian, UO Libraries; 3) Giuseppe Savoca, Professor of Modern and Contemporary Italian Literature at the University of Catania; and 4) Laura Mandell, Department of English, Texas A\&M. Finally, Jeremy Echols is at the moment our web developer and Cinzia Capon is helping with transcriptions and encoding. The encoding process and critical collaborative work by Lollini and his team will enhance enormously the functionality and readability of the $R v f$ in the context of the OPOB by making available crucial documents of the interpretative tradition of the text, as well as its cultural and historical development and reception. In our view, the work done for the 2012 ACLS grant advances, on the one hand, the core idea of our hypertext approach, and, on the other hand, the interpretative challenges of our research. It also provides other scholars and students with the necessary basic tools for discovering new interpretative paths in the documents and data we are making available.

After terminating transcription and encoding, the link Manuscripts in the OPOB will include the Codex Queriniano D II 21. This manuscript is one of the least studied of the early Petrarchan "documents" of the Rvf and one of the most revealing. It is a fair copy in an accurate hand that follows the graphological matrices inherent in Petrarch's own manuscripts (Vatican Latino 3195 and 3196): sonnets are copied two verses per line across the page in a twocolumn format, as are canzoni, ballate, and madrigals.

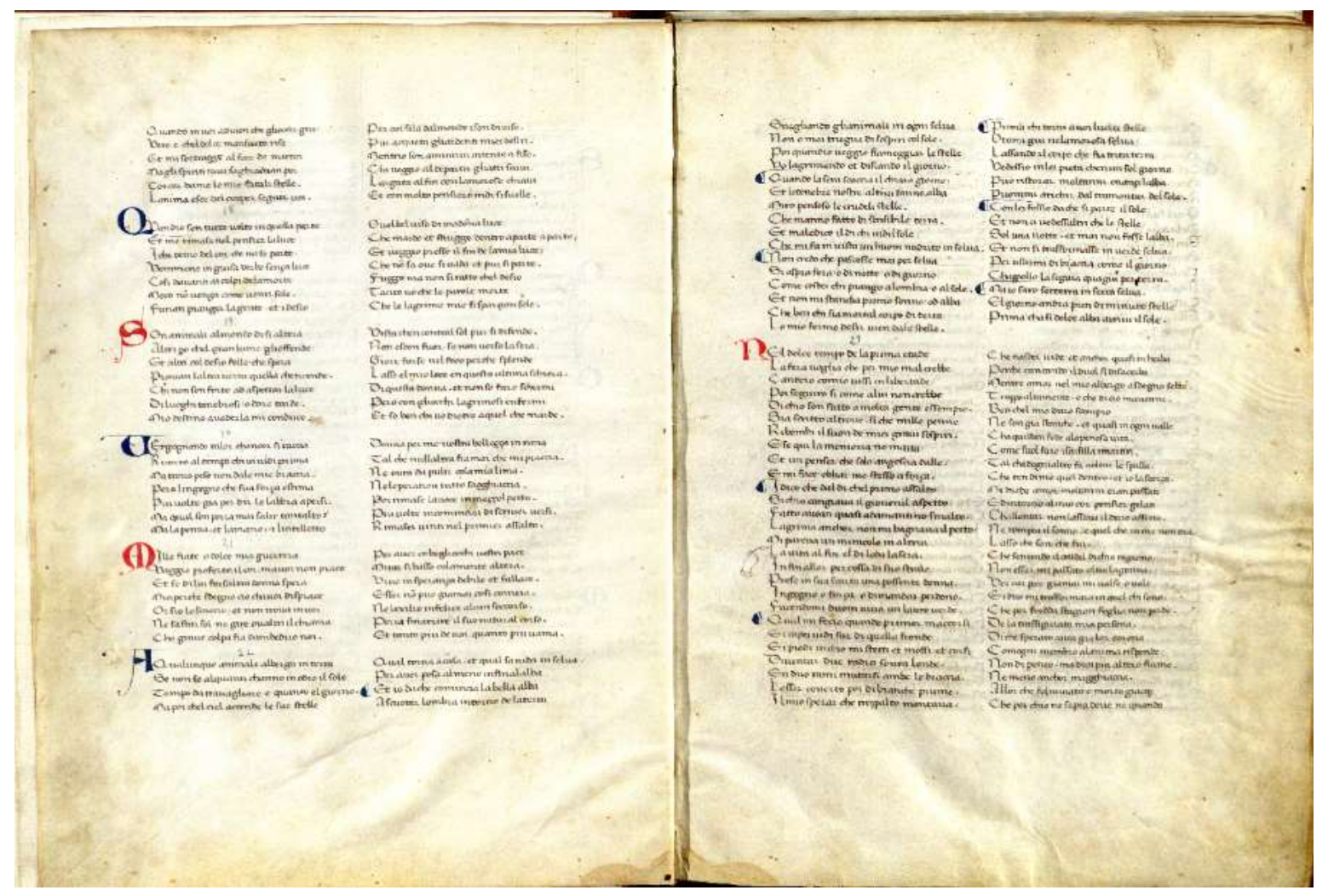


The following image shows how this manuscript is transcribed using T-PEN software:

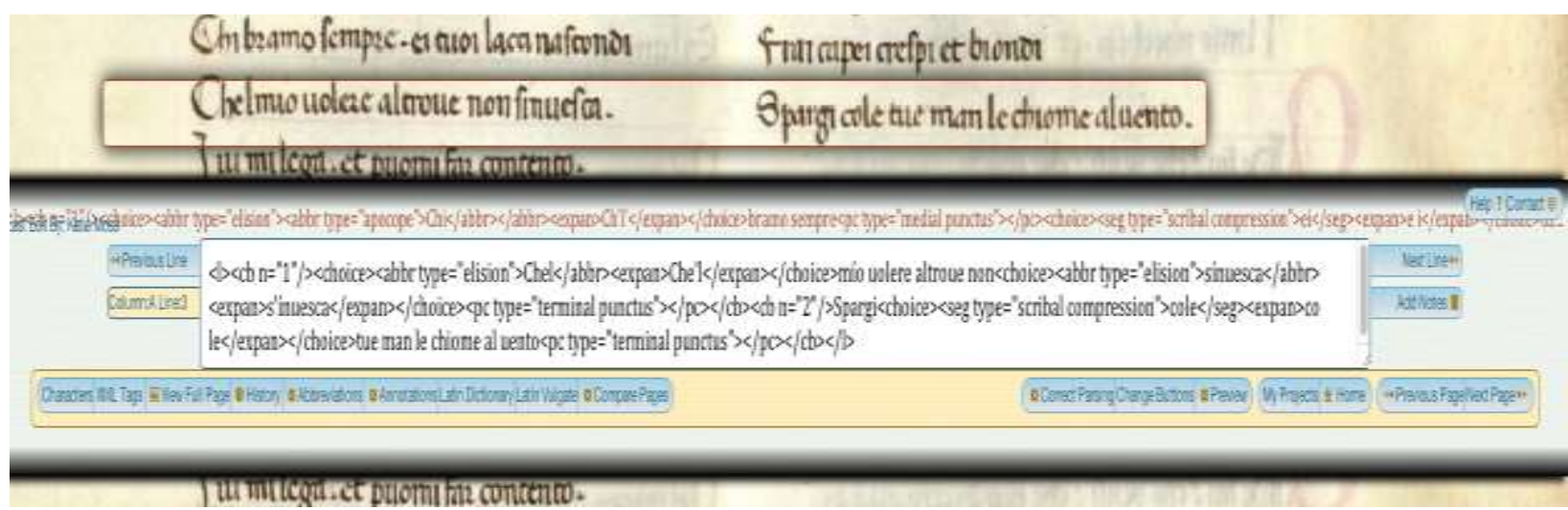

The link Incunabula in the OPOB will include the above mentioned editio princeps of the Canzoniere. While most copies of this first printed edition are known for their uniquely sparse visual presentation, without commentary or other paratextual features, the Queriniana copy of the editio princeps is famous for its extensive illustrations that serve as elaborate glosses of fundamental natural motifs in the poems.

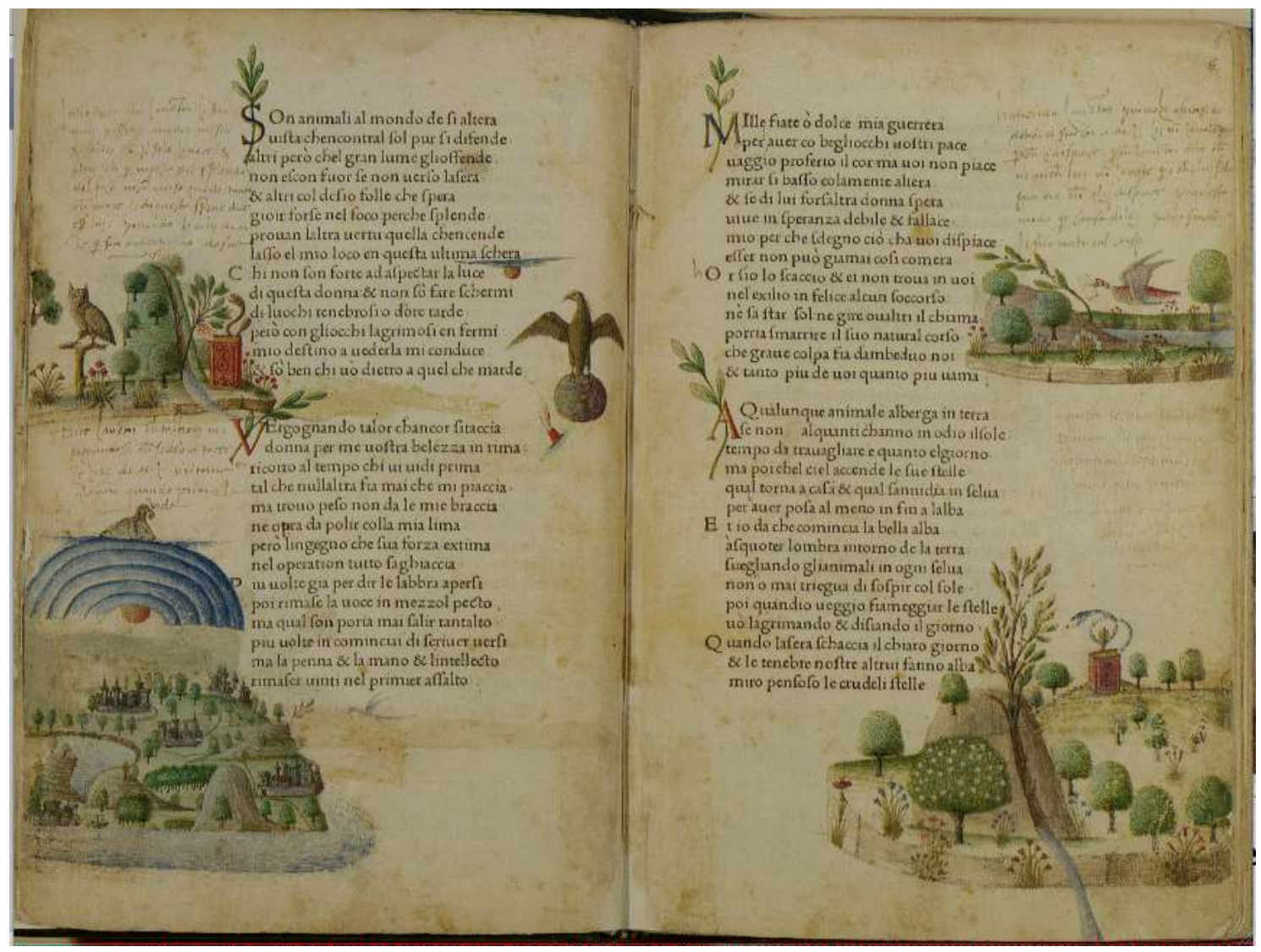


The transcription of the incunabulum is particularly complex as it includes marginal glosses and illustrative vignettes for each poem. The following images show the transcribing procedure of the text:

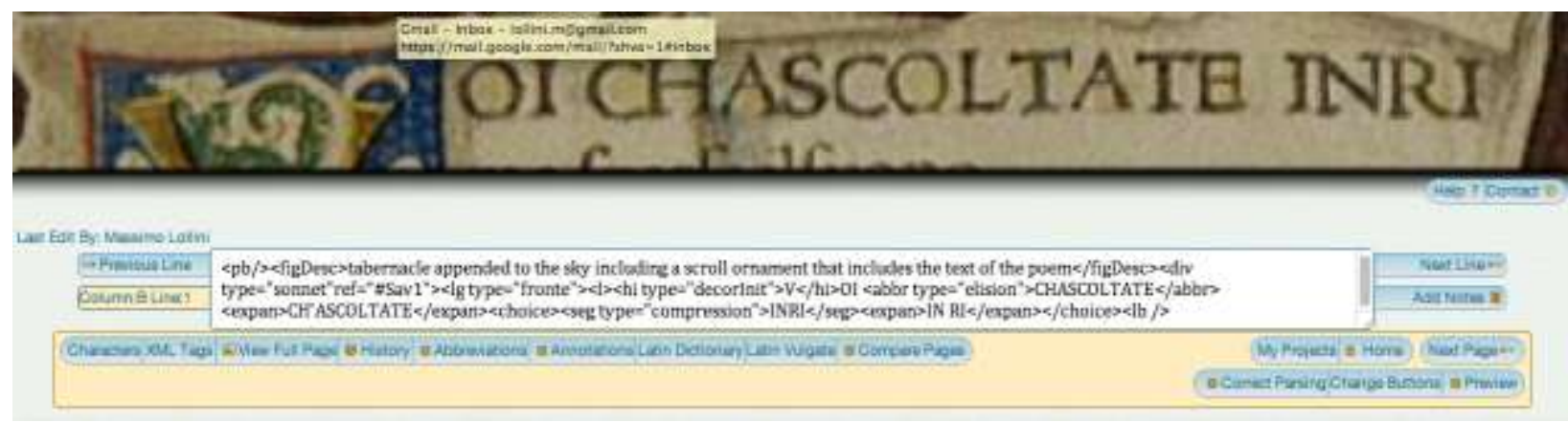

And for the handwritten glosses:

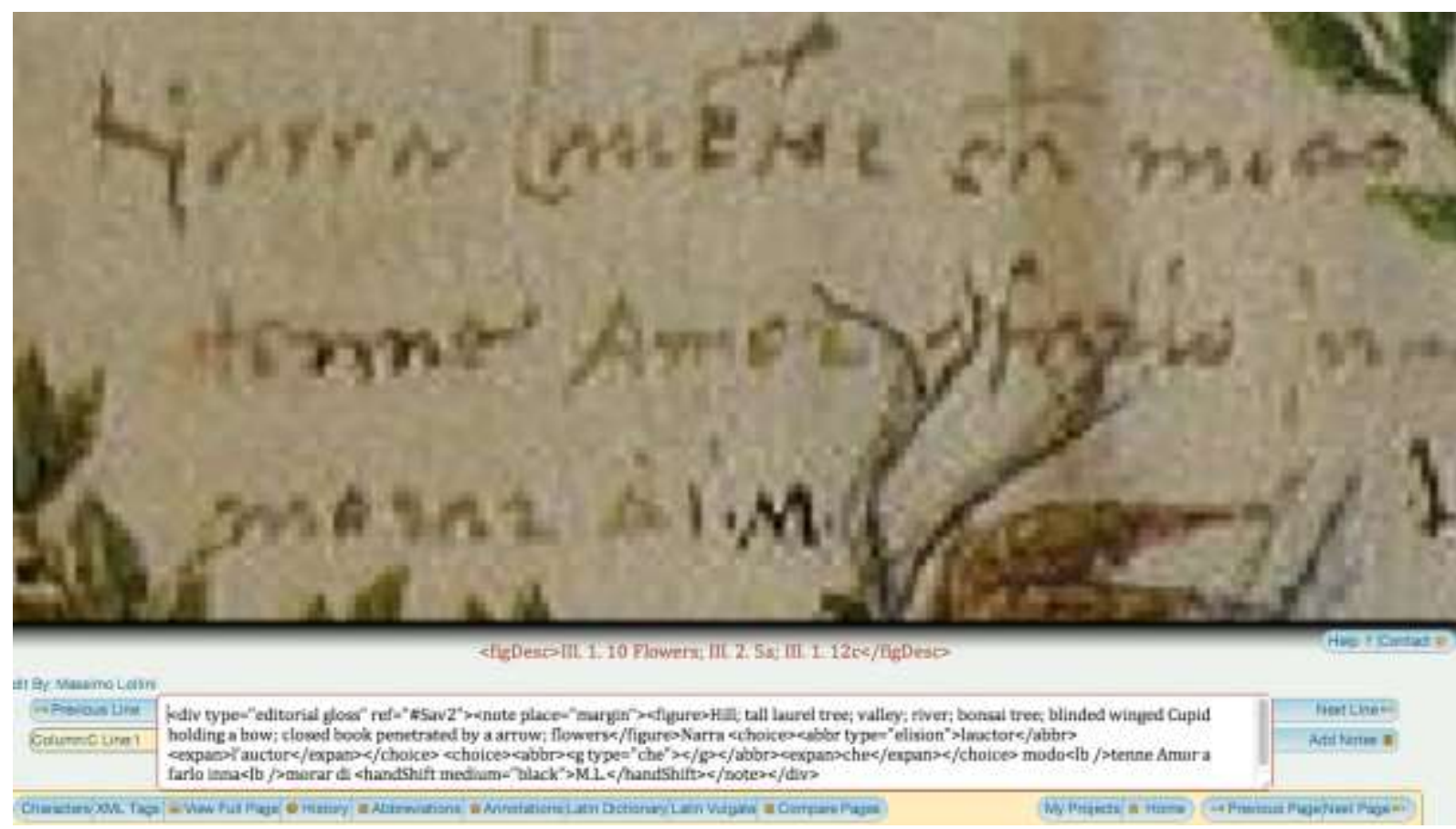

The extensive code written to transcribe the few lines of the gloss gives an idea of the complexity of the operation. Finally, the following screenshot gives an idea of the procedure we are following to encode and describe the miniatures associated to the glosses: 


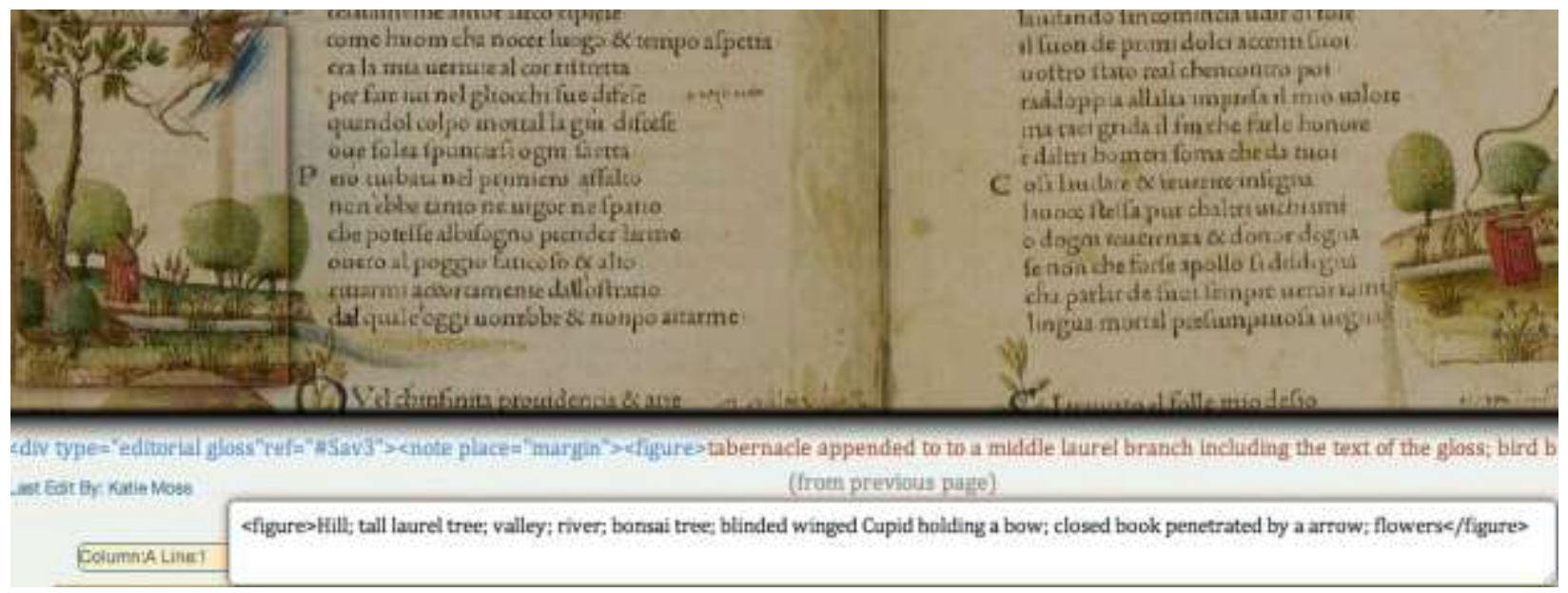

The Future: Preservation, Encoding, and Interpretation

Digital technology is instrumental for taking critical advantage of previous technologies through a process of remediation of the texts we inherited from the past. We are aware of the humanist root of modern philology that came to life along with the technology of the book. One could even argue that the textual fluidity theorized for example by John Bryant, which is often discussed in current debates on digital humanities, was already perceived by early humanists. However, Bryant follows Derrida's disregard of "nostalgia for origins" and of the idea of a truth free from "free-play." Bryant and Derrida suggest that the freeplay of the fluid text leads to a transcendence beyond "man and humanism" and point out the need for new ways of reading, interpreting, and teaching, favoring a mode of interpretation that de-centers meaning and is happy with given and existing fragments of signification (10).

The OPOB takes into consideration the basic fluidity of texts as it has been identified by modern criticism as the first step of digital philology. Moreover, our project addresses some fundamental pitfalls of humanist philology: the tendency to limit the philological operation to a purely restorative and conservative task, or to a dialogue among authors. Nonetheless, we do not emphasize the free-play of fragments of signification but hypertextual construction of meaning, the hermeneutical value of texts through editing, marking up, collating, drawing on phenomenological, comparative, hermeneutic procedures, and moving beyond a deterministic idea of text as a pure fact. We believe in a philologically oriented and creative idea of criticism, intrinsically hermeneutic and based on a relational rather than ontological notion of meaning. This is a humanist idea, hermeneutical, perspectival, and finite. As we move toward the encoding of manuscripts and early books written six centuries ago, we are conscious that a restorative approach is certainly a key factor in the responsibility that the digital humanities have in the preservation of the memory 
of the past. Jerome McGann has insisted on this point, arguing "for the philologian, materials are preserved because their simple existence testifies that they once had value." We share this view, as our present work of transcribing and encoding Codex Queriniano D II 21 and Incunabulum Queriniano G V 15 testifies.

Our aim is first of all to preserve a written and digital memory of these important documents of the Petrarchan tradition as they are, by transcribing and making note of all possible details, even those that we do not understand. Nonetheless, a purely conservative approach is not sufficient to address all the problems involved in the preservation of the memory of our humanist culture. That approach would miss the great opportunity that digital humanists have to re-think the very notion of humanism made possible by the advent of digital technology. From this comes the need to associate the preserving and restorative activity to an interpretative one. This argument is developed and addressed in the editorial to the present issue of Humanist Studies \& the Digital Age.

On the one hand, we know that the "computational notion of the text as a type of data does not coincide with the notion of the text as a product of literary activity" and that the pure "markup thus belongs not to the world of formalisms but to the world of representations". In other words we know that "markup is not a data model" but a "type of data representation," (Buzzetti 67) partial and limited as any type of representation and interpretation. However, besides constraining us within their intrinsic limits, digital philology and textual encoding initiatives provide us with the challenging and stimulating opportunity to re-read and re-interpret the masterpieces of the past from the point of view of a new technology and the new questions we are facing.

The OPOB is willing to take on this challenge by elaborating a project entitled "Texts, Images, and Interpretation in the OPOB." Building on the achievements of the ACLS grant, the new project will allow us to enhance the innovative and humanistic value of the OPOB. Developing and substantiating the philosophical idea of a "more than human humanism," this new interpretative textual annotation will focus in particular on all the geographical and natural references of Petrarch's Canzoniere. Moreover, it will be complemented by the semantic elaboration of the already encoded images of the incunabulum Queriniano. Using Open Access and Semantic Web tools, we will include in our repository-hypertext a digital collection of images from the incunabulum. The images will be linked to the textual thematic network encoded to add an important iconographic element to the interactive net of relationships.

We are inspired, in part, by recent developments in the new discipline called ethnophilology that is working to reinstate at the center of the philological 
task the need to study the manuscripts not exclusively from an authorial perspective but as a witness to the forms of civilizations that produced them. From this viewpoint, the author and the text need to be studied in a broader context that includes not only the historical, cultural environment but also the natural one. This is particularly true for a poet like Petrarch who had an intense rapport with nature throughout his entire life. Our project will show how the sources of his poetry are not only the manuscripts and books from the cultural past but also his profound dialogue with nature that accompanied his love relationship with Laura and triggered his metaphysical speculations. This project "Texts, Images, and Interpretation in the OPOB" will inaugurate the most innovative phase of the $\mathrm{OPOB}$ and provide the opportunity to validate its original approach to hypertext Web publishing. In particular, interpretative encoding and annotation, in conjunction with enhancement of the semantic encoding that links text and images will implement the core idea of the hypertext that we are building in and around the Rvf. This effort will create a collection of textualities broadly conceived to include intersemiotic transpositions that show the evolution of Petrarch's work from manuscript to print and digital culture. The result will be a growing and living archive in which discrete units, entities, and systems are codependent and make sense only in relation to one another. These fragments are witnesses not only to a dialogue among authors and texts but also to a way of inhabiting the world and becoming human in relation to a more than the human environment.

\section{Works Cited}

Benozzo, Francesco. Etnofilologia: Un'introduzione. Napoli: Liguori, 2010. Print.

Bryant, John. The Fluid Text: A Theory of Revision and Editing for Book and Screen. Ann Arbor: University of Michigan Press. 2002. Print.

Buzzetti, Dino. "Digital Representation and the Text Model." New Literary History. 33 (2002): 61-88. Print.

Finneran, Richard J. The Literary Text in the Digital Age. Ann Arbor: University of Michigan Press. 1996. Print. 
Greene, Roland. Post-Petrarchism: Origins and Innovations of the Western Lyric Sequence. Princeton, Princeton University Press. 1991. Print.

McGann, Jerome. "Memory Now." 4Humanities. Web. 2/02/2013. <http://4humanities.org/2012/08/jerome-j-mcgann-memory-now-2/>

Lollini, Massimo. "Return to Philology and Hypertext in and around Petrarch's Rvf." Humanist Studies \& the Digital Age. 1.1 (2011). Web. 15 Sep. 2011. <http://journals.oregondigital.org/hsda/article/view/1101>.

Petrarca, Francesco. Canzoniere; Trionfi. Cur. Cristoforo [Berardi?]. Venezia: Vindelino da Spira, 1470. Incunabulum Queriniano G V 15. Queriniana Library, Brescia. Print.

-----. Canzoniere. Codex Queriniano D II 21, Queriniana Library, Brescia. Print.

Petrarca, Francesco, Gianfranco Contini, and Daniele Ponchiroli. Canzoniere. Torino: G. Einaudi, 1964. Print.

Petrarca, Francesco, and Giuseppe Savoca. Rerum Vulgarium Fragmenta. Firenze: L.S. Olschki, 2008. Print. 